CLINICAL STUDY

\title{
Treatment with the PPAR $\gamma$ agonist rosiglitazone downregulates interleukin-1 receptor antagonist in individuals with metabolic syndrome
}

\author{
Bente Halvorsen $^{1,5}$, Eli Heggen ${ }^{4,5}$, Thor Ueland ${ }^{1,2,5}$, Camilla Smith ${ }^{1,5}$, Wiggo J Sandberg ${ }^{1,5}$, Jan K Damås ${ }^{1}$, \\ Kari Otterdal $^{1,5}$, Serena Tonstad ${ }^{4,5}$ and Pål Aukrust ${ }^{1,3,5}$ \\ ${ }^{1}$ Research Institute for Internal Medicine, ${ }^{2}$ Section of Endocrinology, ${ }^{3}$ Section of Clinical Immunology and Infectious Diseases, ${ }^{4}$ Department of Preventive \\ Cardiology, Ullevål Hospital, Oslo University Hospital, Oslo, Norway and ${ }^{5}$ Faculty of Medicine, University of Oslo, Oslo, Norway
}

(Correspondence should be addressed to B Halvorsen at Research Institute of Internal Medicine, Rikshospitalet, Oslo University Hospital, N-O027 Oslo, Norway; Email: bente.halvorsen@rr-research.no)

\begin{abstract}
Objectives: Thiazolidinediones (TZDs) reduce insulin resistance, but also have pleiotropic properties including effects on inflammation. The balance between protective and proatherogenic effects may differ in various patient populations. We studied the effect of rosiglitazone on inflammatory markers in patients with metabolic syndrome (MetSyn).

Methods: In a cross-over randomized controlled trial, 23 subjects with MetSyn were assigned to treatment with rosiglitazone that was uptitrated from $4 \mathrm{mg} /$ day for 6 weeks followed by $8 \mathrm{mg} /$ day for 6 weeks or matching placebo for 12 weeks, and then to the opposite treatment for 12 weeks. Plasma levels of inflammatory and metabolic markers were measured during follow-up.

Results: Our main findings were i) compared to placebo, rosiglitazone significantly decreased the plasma levels of the naturally occurring interleukin (IL) 1 inhibitor, IL1 receptor antagonist (IL1Ra; $P=0.001)$, potentially reflecting inflammatory effects on the IL1 system; ii) parallel to this, rosiglitazone decreased plasma levels of IL10 $(P=0.029)$ further suggesting inflammatory effects; iii) rosiglitazone decreased uric acid levels $(P=0.001)$, and monocyte chemoattractant protein-1 $(P=0.05)$ and $C$-reactive protein $(P=0.06)$ tended to be lower after rosiglitazone than placebo, suggesting potential pro- and anti-inflammatory effects simultaneously and iv) in vitro, rosiglitazone enhanced IL1Ra and decreased IL1 $\beta$ in THP-1 monocytes, illustrating the complex effects of these medications, potentially exhibiting anti-inflammatory effects on the IL1 system in certain tissues or cells at least at certain concentrations.

Conclusion: Our findings suggest inflammatory effects on the IL1 system during rosiglitazone therapy in MetSyn. However, anti-inflammatory effects were also observed, and the net effect of TZDs in MetSyn should be further investigated.
\end{abstract}

European Journal of Endocrinology 162 267-273

\section{Introduction}

Patients with metabolic syndrome (MetSyn) have a high risk of developing cardiovascular morbidity and mortality (1). Each of the risk factors comprising this syndrome interacts synergistically, causing or accelerating the progression of atherosclerosis. Thus, although it is not known whether insulin resistance (IR) universally precedes the development of MetSyn, this syndrome is a precursor of type 2 diabetes. However, the classical risk factors may not alone account for the increased risk of cardiovascular disease in MetSyn. In the last decade, experimental and clinical data have illuminated a role of inflammation in atherogenesis (2), and this concept could also be applied to patients with MetSyn. Thus, several studies have shown raised serum levels of inflammatory markers such as C-reactive protein (CRP) (3), interleukin (IL)6 (4), and tumor necrosis factor $\alpha$ (TNF $\alpha)$ (5) in these patients. In fact, it has been suggested that the MetSyn, type 2 diabetes, and atherosclerotic disorders are multifactorial diseases, which are all characterized by chronic inflammation $(1,6)$.

Thiazolidinediones (TZDs) are a class of drugs that reduce IR and thereby are used in clinical practice to treat patients with type 2 diabetes (7). TZDs are selective and potent agonists for the peroxisome proliferatoractivated receptor (PPAR) $\gamma$, and influence the transcription of genes that regulate lipid and glucose metabolism (8). Recent data suggest that PPAR $\gamma$ agonists also may 
modulate other biological processes that are involved in atherosclerosis, including inflammation $(9,10)$. For example, the PPAR $\gamma$ agonist rosiglitazone reduced serum concentrations of CRP in patients with type 2 diabetes and in patients with coronary artery disease (CAD) without diabetes (11). Some of the antiinflammatory effects of TZDs may be secondary to their metabolic effects, but could also, at least in part, be a direct effect of PPAR $\gamma$ activation. However, the effect of $\operatorname{PPAR} \gamma$ agonists on inflammation is still unclear, and few studies are available regarding the potential anti-inflammatory effects of PPAR $\gamma$ agonists in MetSyn prior to the development of diabetes. On the other hand, recent studies have suggested that PPAR $\gamma$ agonists have other effects that may exacerbate CAD (12).

The purpose of this study was to elucidate the effect of the PPAR $\gamma$ agonist rosiglitazone on inflammatory responses in patients with MetSyn. In a placebocontrolled, cross-over study, we compared the effects of rosiglitazone treatment for 12 weeks with placebo on a wide range of inflammatory markers in patient with MetSyn, who had not yet developed diabetes.

\section{Materials and methods}

\section{Subjects}

Subjects were recruited from the patient charts at the Department of Preventive Cardiology at Ullevål Hospital, Oslo University Hospital, Oslo, Norway and by newspaper advertisement, and were screened for enrollment in the study in November and December 2004. Eligible subjects were nonsmoking men (30-75 years) and women (45-75 years, at least 1 year postmenopausal or oophorectomized). All individuals had two or more of the following National Cholesterol Education Program (NCEP) 2001 criteria for MetSyn in addition to body mass index (BMI) $>25 \mathrm{~kg} / \mathrm{m}^{2}$ : i) waist $>102 \mathrm{~cm}$ (men) or $>88 \mathrm{~cm}$ (women); ii) fasting triglycerides $>1.69 \mathrm{mmol} / \mathrm{l}$; iii) high-density lipoprotein (HDL) cholesterol $<1.03 \mathrm{mmol} / \mathrm{l}$ (men) or $<1.29 \mathrm{mmol} / \mathrm{l}$ (women); iv) blood pressure $\geq 130 / \geq 85 \mathrm{mmHg}$; and v) fasting plasma glucose $\geq 6.1 \mathrm{mmol} / \mathrm{l}$. Subjects were not included if they i) had taken statins, anti-hypertensives, anti-diabetes drugs, or hormone substitution (women); ii) had any known autoimmune or chronic inflammatory disease or active infection; iii) had any known cardiovascular disease, including $\mathrm{CAD}$ and heart failure; iv) were at need for statins, anti-hypertensives, or anti-diabetic drugs according to guidelines or physicians judgment; v) had fasting plasma glucose $>8 \mathrm{mmol} / \mathrm{l}$, fasting triglycerides $>7.0 \mathrm{mmol} / \mathrm{l}$, systolic blood pressure $\geq 160 \mathrm{mmHg}$, or diastolic $\geq 100 \mathrm{mmHg}$; vi) had used omega-3 fatty acid preparations within 2 weeks of screening; vii) were abusing alcohol or narcotics; viii) had any unstable medical or psychiatric disease; ix) had hemoglobin concentrations below the reference level at screening; $x$ ) had aspartate aminotransferase or alanine aminotransferase $>2 \times$ upper reference level at screening; and xi) had any liver or kidney disease; or xii) had BMI $>40 \mathrm{~kg} / \mathrm{m}^{2}$.

\section{Rosiglitazone and placebo tablets}

Visually matched tablets containing either rosiglitazone (Avandia, 4 and $8 \mathrm{mg}$ ) or placebo were provided by GlaxoSmithKline.

\section{Study design}

Following screening, subjects were randomized to treatment with rosiglitazone that was uptitrated from $4 \mathrm{mg} /$ day for 6 weeks followed by $8 \mathrm{mg} /$ day for 6 weeks or matching placebo tablets for 12 weeks, and then to the opposite treatment (placebo or rosiglitazone) for 12 weeks for a total of 24 weeks. The patients were instructed to keep their diet and body weight stable during the study. Blood sampling and clinical evaluations were performed at the day of screening, randomization (baseline), after 12 weeks and at 24 weeks at the end of the study. The study was approved by the regional ethical committee and the Norwegian Medicines Agency (Eudract number 2004-001026-24) and conformed to the Declaration of Helsinki. Written informed consent was obtained from each patient.

\section{Blood sampling protocol}

Blood samples were drawn between 0800 and $1100 \mathrm{~h}$ after an overnight fast into pyrogen-free EDTA tubes (plasma) or tubes without any additives (serum), immediately immersed in melting ice, and centrifuged within $30 \mathrm{~min}$ at $2000 \boldsymbol{g}$ for $20 \mathrm{~min}$ (platelet-poor plasma) or after coagulation (serum). Serum and plasma were stored at $-80{ }^{\circ} \mathrm{C}$ until analysis, and samples were thawed only once.

\section{Cell culture}

The human monocytic cell line THP-1 (American Type Culture Collection, Rockville, MD, USA) was cultured for 4 days in RPMI 1640 (PAA Laboratories, Pasching, Austria) supplemented with $2.5 \%$ fetal bovine serum (Gibco) in the presence of recombinant human TNF $\alpha$ ( $5 \mathrm{ng} / \mathrm{ml}, \mathrm{R} \& D$ Systems, Minneapolis, MN, USA) before further incubation with or without different concentrations of the PPAR-agonist rosiglitazone (Cayman Chemical, Ann Arbor, MI, USA). Cell pellets and cell-free supernatants were stored at indicated time points at $-70{ }^{\circ} \mathrm{C}$ until further analysis. Endotoxin levels in media and rosiglitazone were $<10 \mathrm{pg} / \mathrm{ml}$ (limulus amoebocyte lysate test; BioWhittaker, Walkersville, MD, USA). 


\section{Biochemical and immunological analysis}

Routine clinical chemistry, including leukocyte and leukocyte subset counts, was performed as previously reported $(13,14)$. Serum glucose was analyzed by the glucose hexokinase method, and $\mathrm{HbA} 1 \mathrm{c}$ was analyzed by colorimetric and immunoturbidimetric methods in whole blood (Cobas Integra System, Roche Diagnostics $\mathrm{GmbH})$. Serum levels of insulin were measured by a RIA method (Insulin Coat-A-Count, DPC, Los Angeles, CA, USA). IR and pancreatic B-cell function were calculated by the homeostasis model assessment (HOMA-IR and HOMA-B respectively) method (15). Total cholesterol, low-density lipoprotein (LDL) and HDL cholesterol, and triglycerides were measured using enzymatic colorimetric tests (Hitachi 917; Roche Diagnostics). CRP was measured in serum using a high-sensitivity particle-enhanced immunoturbidimetric assay on a modular platform (Roche Diagnostics). Plasma levels of IL1 $\beta$, IL6, IL10, monocyte chemoattractant protein (MCP)1, and TNF $\alpha$ were determined by using a multiplex cytokine immunoassay from Bio-Rad Laboratories, and were further analyzed on a Multiplex Analyser (Bio-Rad Laboratories). Plasma levels of neopterin and soluble CD40 ligand (sCD40L) were measured by enzyme immunoassays (EIAs) provided by Brahms (Henninsdorf, Germany) and Bender MedSystems (Vienna, Austria) respectively. Plasma levels of osteoprotegerin, IL1 receptor antagonist 132(IL1Ra), CC chemokine ligand 21 (CCL21), and soluble TNF receptor type 1 (sTNF-R1) were measured by EIAs obtained from R\&D systems. Plasma levels of von Willebrand factor were determined by EIA as reported elsewhere (16). Concentrations of IL1 $\beta$ and ILRa in monocyte supernatants were analyzed by EIAs (R\&D Systems). The intra- and inter-assay coefficient of variation was $<10 \%$ for all assays.

\section{Statistical analysis}

Data are presented as means with s.D. with the exception of CRP for which median and interquartile range values are shown. Screening characteristics of the included patients at baseline and blood test parameters were compared using Student's t-test. Analysis for the presence of period or carry-over effects revealed no significant effects (data not shown). Thus, at the end of each period (rosiglitazone or placebo), results were combined for both groups and shown for all participants. The estimated treatment effects (values after rosiglitazone compared with values after placebo) were analyzed with paired $t$-test for laboratory parameters and Wilcoxon signed rank test for inflammatory profile including CRP (because of a skewed distribution as estimated by the KolmogorovSmirnov test). Throughout, we report two-tailed $P$ values, and values $<0.05$ were considered significant. However, particular attention should be directed toward smaller $P$ values $<0.01$, because a considerable number of $P$ values have been calculated.

\section{Results \\ Subject disposition and characteristics}

Twenty-six subjects were screened for inclusion in the study. One potential subject was not randomized because he was diagnosed with chronic lymphatic leukemia at screening. One male subject withdrew on the visit after randomization because of problems with venipuncture. One female subject stopped taking study medication (placebo) due to diarrhea and withdrew from the study. This left 11 female and 12 male participants.

At baseline, 12 subjects were assigned to receive rosiglitazone first, and 11 subjects were assigned to receive placebo first and each group switched to the opposite condition after 12 weeks. Baseline characteristics were similar in both groups with the exception of HDL cholesterol, which was higher in the group that started on placebo (Table 1). During the study period, there were no significant differences in changes in body weight, BMI, waist circumference, heart rate, or systolic and diastolic blood pressure between the two groups (data not shown; $P>0.15$ for all).

\section{Metabolic effects}

Total cholesterol increased significantly on rosiglitazone versus placebo, primarily reflecting an increase in LDL

Table 1 Screening characteristics of the study subjects. Data are given as mean (S.D).

\begin{tabular}{lll}
\hline & $\begin{array}{l}\text { Rosiglitazone } \\
\text { first }(n=12)\end{array}$ & $\begin{array}{l}\text { Placebo first } \\
(n=11)\end{array}$ \\
\hline $\begin{array}{ll}\text { Demographic and clinical characteristics } \\
\text { Males/females }\end{array}$ & $7 / 5$ \\
Age (years) & $52.2(6.6)$ & $55.3(15.8)$ \\
Body mass index (kg/m $\left.{ }^{2}\right)$ & $32.0(4.5)$ & $31.9(4.4)$ \\
Waist circumference $(\mathrm{cm})$ & $104(7)$ & $105(10)$ \\
Systolic blood pressure $(\mathrm{mmHg})$ & $135(11)$ & $140(10)$ \\
Diastolic blood pressure (mmHg) & $90(4)$ & $90(4)$ \\
Heart rate/min & $61(3)$ & $65(5)$ \\
& & \\
Fasting laboratory parameters & $5.2(0.9)$ & $5.6(0.8)$ \\
Total cholesterol (mmol/l) & $1.2(0.1)$ & $1.6(0.4)^{\star}$ \\
HDL cholesterol (mmol/l) & $3.6(0.9)$ & $3.7(0.6)$ \\
LDL cholesterol (mmol/l) & $1.7(0.6)$ & $1.5(1.2)$ \\
Triglycerides (mmol/l) & $5.3(0.6)$ & $5.2(0.3)$ \\
Glucose (mmol/l) & $65(31)$ & $61(29)$ \\
Insulin (pmol/l) & $3.9(3.7)$ & $3.2(3.2)$ \\
C-reactive protein (mg/l) & $3.0(0.7)$ & $2.5(0.5)$ \\
Metabolic syndrome & & \\
components (numbers $\left.{ }^{\mathrm{a}}\right)$ & & \\
\hline
\end{tabular}

\section{${ }^{\star} P=0.006$.}

${ }^{a}$ All individuals had two or more of the criteria for MetSyn (National Cholesterol Education Program, 2001) in addition to body mass index $>25 \mathrm{~kg} / \mathrm{m}^{2}$ (see Material and methods). 
Table 2 Laboratory parameters at baseline and at the end of each treatment period (n=23). Mean (s.D.) values are shown.

\begin{tabular}{|c|c|c|c|c|}
\hline & Baseline & Rosiglitazone & Placebo & $P$ value ${ }^{a}$ \\
\hline \multicolumn{5}{|l|}{ Lipids and lipoproteins } \\
\hline Total cholesterol $(\mathrm{mmol} / \mathrm{l})$ & $5.40(0.93)$ & $6.13(0.9)$ & $5.40(0.73)$ & $<0.001$ \\
\hline HDL cholesterol (mmol/l) & $1.34(0.41)$ & $1.38(0.38)$ & $1.31(0.32)$ & 0.1 \\
\hline LDL cholesterol (mmol/l) & $3.51(0.81)$ & $4.07(0.90)$ & $3.56(0.74)$ & 0.003 \\
\hline Triglycerides $(\mathrm{mmol} / \mathrm{l})$ & $1.68(0.84)$ & $1.85(1.15)$ & $1.73(1.01)$ & 0.6 \\
\hline Apolipoprotein B (g/l) & $1.01(0.21)$ & $1.00(0.22)$ & $0.94(0.17)$ & 0.08 \\
\hline Apolipoprotein A1 (g/l) & $1.36(0.25)$ & $1.27(0.26)$ & $1.34(0.21)$ & 0.08 \\
\hline Apolipoprotein B/A1 & $0.77(0.21)$ & $0.84(0.33)$ & $0.72(0.18)$ & 0.02 \\
\hline \multicolumn{5}{|l|}{ Carbohydrate metabolism } \\
\hline Glucose $(\mathrm{mmol} / \mathrm{l})$ & $5.20(0.51)$ & $5.19(0.51)$ & $5.31(0.57)$ & 0.3 \\
\hline Insulin (pmol/l) & $72(45)$ & $45(23)$ & $59(31)$ & 0.01 \\
\hline Hemoglobin A1c (\%) & $5.65(0.28)$ & $5.74(0.27)$ & $5.60(0.27)$ & 0.02 \\
\hline HOMA B $\left(\%^{b}\right)$ & $105(37)$ & $75(24)$ & $88(32)$ & 0.04 \\
\hline HOMA IR ${ }^{\mathrm{b}}$ & $1.39(0.87)$ & $0.84(0.46)$ & $1.12(0.59)$ & 0.03 \\
\hline \multicolumn{5}{|l|}{ Clinical chemistry } \\
\hline Uric acid $(\mu \mathrm{mol} / \mathrm{l})$ & $372(65)$ & $365(89)$ & $408(82)$ & 0.001 \\
\hline Creatinine $(\mu \mathrm{mol} / \mathrm{l})$ & $72(14)$ & $72(15)$ & $70(13)$ & 0.02 \\
\hline ASAT (U/I) & $26(7)$ & $24(6)$ & $28(8)$ & 0.04 \\
\hline ALAT (U/I) & $35(18)$ & $27(11)$ & $35(17)$ & 0.001 \\
\hline \multicolumn{5}{|l|}{ Hematology } \\
\hline Hemoglobin (g/dl) & $14.5(0.8)$ & $13.7(1.1)$ & $14.5(0.8)$ & $<0.001$ \\
\hline Red blood cells $\left(10^{12} / l\right)$ & $4.85(0.30)$ & $4.63(0.40)$ & $4.84(0.36)$ & $<0.001$ \\
\hline Platelets $\left(10^{9} / \mathrm{l}\right)$ & $263(59)$ & $238(51)$ & $246(51)$ & 0.3 \\
\hline White blood cells $\left(10^{9} / \mathrm{l}\right)$ & $5.98(1.48)$ & $5.37(1.19)$ & $5.91(1.28)$ & 0.003 \\
\hline Neutrophils $\left(10^{9} / l\right)$ & $3.34(1.13)$ & $2.77(0.92)$ & $3.20(1.05)$ & 0.01 \\
\hline Lymphocytes $\left(10^{9} / \mathrm{l}\right)$ & $1.90(0.54)$ & $1.88(0.49)$ & $1.98(0.53)$ & 0.08 \\
\hline Monocytes $\left(10^{9} / \mathrm{l}\right)$ & $0.48(0.16)$ & $0.47(0.16)$ & $0.48(0.14)$ & 0.6 \\
\hline Eosinophils $\left(10^{9} / \mathrm{l}\right)$ & $0.19(0.09)$ & $0.18(0.09)$ & $0.19(0.10)$ & 0.5 \\
\hline Basophils $\left(10^{9} / \mathrm{I}\right)$ & $0.10(0.11)$ & $0.06(0.04)$ & $0.06(0.03)$ & 0.9 \\
\hline
\end{tabular}

${ }^{\text {aP }}$ aired $t$-tests.

${ }^{\mathrm{b}}$ Insulin resistance and pancreatic B-cell function were calculated by the homeostasis model assessment (HOMA-IR and HOMA-B respectively) method.

cholesterol (Table 2). The apolipoprotein B/A1 ratio was also significantly higher on rosiglitazone versus placebo. As for the other lipid parameters, there were no significant differences between rosiglitazone and placebo periods (Table 2). Whereas there were no differences in fasting glucose levels, fasting insulin concentrations were lower after rosiglitazone treatment than after placebo treatment (Table 2). HbA1c concentration was higher after the rosiglitazone period versus the placebo period (Table 2), but all individuals had $\mathrm{HbAlc}$ levels within normal limits during the study period. Moreover, after rosiglitazone therapy, there was a decrease in IR (HOMA-IR) accompanied by a decrease in insulin release or pancreatic B-cell function (HOMA-B), potentially reflecting improved insulin sensitivity during rosiglitazone therapy (Table 2).

Table 3 Inflammatory profile at baseline and at the end of each treatment period $(n=23)$. Data are given as mean (s.D.) (normally distributed data) except for C-reactive protein (CRP), interleukin (IL)1 $\beta$, and ILRa for which median and 25 and 75 th percentiles are shown (not normally distributed data).

\begin{tabular}{lllll}
\hline & Baseline & Rosiglitazone & Placebo & $\boldsymbol{P}_{\text {value }}$ \\
\hline CRP $(\mathrm{mg} / \mathrm{l})$ & $3.0(1.6,5.1)$ & $1.6(1.1,2.6)$ & $2.9(1.6,3.5)$ & 0.06 \\
Tiff $(\mathrm{pg} / \mathrm{ml})$ & $0.79(0.34)$ & $0.73(0.40)$ & $0.72(0.40)$ & 0.6 \\
sTNF-R1 $(\mathrm{ng} / \mathrm{ml})$ & $1.11(0.16)$ & $1.16(0.17)$ & $1.10(0.17)$ & 0.019 \\
IL10 $(\mathrm{pg} / \mathrm{ml})$ & $1.18(1.41)$ & $0.89(1.18)$ & $1.10(1.19)$ & 0.029 \\
IL1 $\beta(\mathrm{pg} / \mathrm{ml})$ & $0.12(0.09,0.23)$ & $0.11(0.08,0.18)$ & $0.11(0.08,0.14)$ & 0.1 \\
IL1Ra $(\mathrm{pg} / \mathrm{ml})$ & $90(54,196)$ & $54(35,85)$ & $101(59,138)$ & 0.001 \\
IL6 $(\mathrm{pg} / \mathrm{ml})$ & $0.16(0.07)$ & $0.15(0.07)$ & $0.16(0.10)$ & 0.8 \\
MCP1 $(\mathrm{pg} / \mathrm{ml})$ & $203(165)$ & $201(150)$ & $2407(230)$ & 0.052 \\
CCL21 $(\mathrm{pg} / \mathrm{ml})$ & $244(157)$ & $236(154)$ & $1.39(0.40)$ & 0.5 \\
OPG $(\mathrm{ng} / \mathrm{ml})$ & $1.47(0.51)$ & $1.38(0.47)$ & $8.31(1.76)$ & 0.8 \\
Neopterin $(\mathrm{nM})$ & $7.99(1.90)$ & $8.21(1.90)$ & $8.33(4.22)$ & 0.3 \\
sCD40L $(\mathrm{ng} / \mathrm{ml})$ & $2.41(2.15)$ & $7.16(4.01)$ & & \\
\hline
\end{tabular}

$\mathrm{AU}$, arbitrary units.

aWilcoxon signed rank test comparing rosiglitazone versus placebo. 


\section{Serum and plasma levels of inflammatory parameters}

Total leukocyte counts were reduced after rosiglitazone compared to placebo and primarily reflected a decrease in the numbers of neutrophils (Table 2). Also, CRP concentration decreased after rosiglitazone versus placebo, although the difference did not reach statistical significance $(P=0.06$, Table 3$)$. Uric acid is thought, at least partly, to reflect the degree of inflammation and oxidative stress (17), and notably, uric acid levels were significantly lower after rosiglitazone than placebo (Table 2). Chemokines like MCP1 are reported to play a major role in atherogenesis (reviewed by (18)), and MCP1 levels were decreased after rosiglitazone treatment compared to placebo, although the difference did not reach statistical significance $(P=0.05)$. In contrast to these antiinflammatory effects, the decrease in IL10 after rosiglitazone as compared with placebo may potentially reflect inflammatory effects of this medication (Table 3 ). IL1Ra is the natural inhibitor of IL1, possessing potent anti-inflammatory effects $(19,20)$, and notably, IL1Ra was significantly decreased on rosiglitazone treatment compared to placebo accompanied by no changes in IL1 $\beta$, suggesting inflammatory effects on the IL1 system (Table 3). As for the other markers, there were no significant effects of rosiglitazone as compared with placebo (Table 3).

\section{Safety and tolerability}

Three subjects developed mild to moderate pitting edema, and two subjects reported leg cramps while taking rosiglitazone. Liver transaminase concentrations were lower after rosiglitazone than placebo while creatinine concentrations were lower after placebo, but in general, the levels were within normal limit in both treatment groups (Table 2). There was a significant decrease in hemoglobin levels and red blood cell counts in the rosiglitazone group as compared with the placebo group, but again, the levels remained within normal limits (Table 2).

\section{Effect of rosiglitazone on the IL1 system in vitro}

A major finding in the present study was the significant decrease in plasma levels of IL1Ra after rosiglitazone treatment as compared with placebo treatment. To further elucidate this issue, we examined the ability of rosiglitazone to modulate the IL1 system in vitro. As can be seen in Fig. 1, in THP-1 monocytes that had been exposed to TNF $\alpha(5 \mathrm{ng} / \mathrm{ml})$ for $96 \mathrm{~h}$, representing an attempt to mimic the microenvironment in patients with low-grade systemic inflammation, rosiglitazone significantly downregulated the release of IL1 $\beta$ and enhanced the release of IL1Ra after culturing for
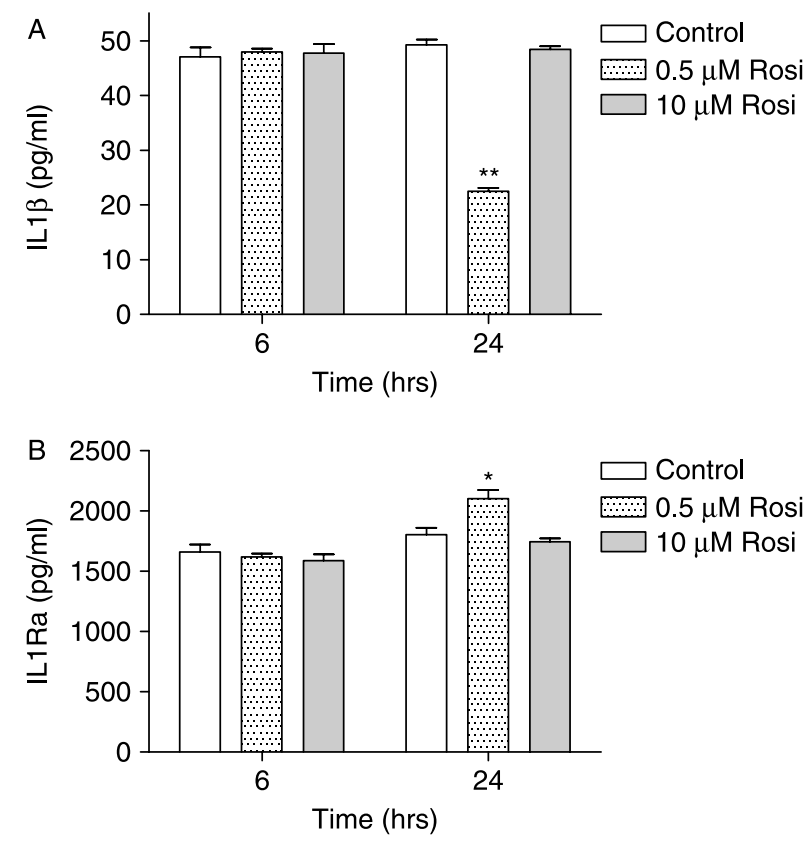

Figure 1 The release of IL1 $\beta(A)$ and ILRa $(B)$ in THP-1 monocytes that had been pre-activated with TNF- $\alpha(5 \mathrm{ng} / \mathrm{ml})$ before being exposed to different concentrations of rosiglitazone (Rosi) for 6 and $24 \mathrm{~h}$. The cytokines were measured by ELISA, and data are presented as mean \pm S.E.M., $n=8$. ${ }^{*} P<0.05$ and ${ }^{* \star} P<0.001$ versus controls.

$24 \mathrm{~h}$. However, this effect was restricted to low-dose rosiglitazone $(0.5 \mu \mathrm{M})$ and was not seen at a higher concentration (10 $\mu$ M; Fig. 1).

\section{Discussion}

PPAR $\gamma$ agonists are widely used in the treatment of type 2 diabetes for their insulin-sensitizing properties (7). Also, there is evidence that TZDs exert a number of pleiotropic effects that may play an important role in the treatment of type 2 diabetes and potentially also in other cardiovascular disorders $(12,21)$. These effects include favorable outcome on blood pressure and potentially anti-inflammatory net effects. Most in vivo studies have been performed in patients with type 2 diabetes, but previously, rosiglitazone was shown to increase plaque collagen content and downregulate circulating levels of CRP and serum amyloid A in nondiabetic patients with symptomatic carotid artery stenosis (22). Moreover, previous reports have shown attenuating effects of rosiglitazone on plasma levels of IL6, IL18, and CRP in patients with MetSyn $(3,23)$. However, studies on the in vivo effects of rosiglitazone on inflammation have been somewhat conflicting, at least partly due to differences in study populations (e.g. healthy controls, obese patients, and patients with type 2 diabetes). In the present study, we extend previous findings by showing a marked downregulatory effect on plasma levels IL1Ra as the 
major finding. Based on the ability of ILRa to inhibit the binding of IL1 to its membrane-bound receptor $(24,25)$, these findings may suggest inflammatory net effects on the IL1 system during rosiglitazone therapy.

Although IL1Ra might be viewed as an acute phase protein, since it has been shown that the injection of IL1 and IL6, both being potent inducers of CRP, in humans leads to a rapid rise in blood IL1Ra levels (24), the decline in IL1Ra levels, the natural inhibitor of IL1 $\alpha$ and IL1 $\beta$ (24-26), during rosiglitazone therapy suggests inflammatory net effects on the IL1 system. In fact, the decline in ILRa levels was accompanied by no changes in IL1 $\beta$ levels, further supporting inflammatory net effects on the IL1 system during such therapy (20). The IL1 system is upstream in the inflammatory cascade, and IL1-related pathways appear to be of major importance in various inflammatory conditions such as atherosclerosis (27) and several autoimmune disorders (28). IL1 has also been linked to obesity and MetSyn $(29,30)$, potentially contributing to the high risk of cardiovascular disease in these individuals. Adipose tissue is an important source of IL1Ra $(31,32)$. However, in the current study, rosiglitazone had no effect on body weight, BMI, or waist circumference suggesting more direct effects of rosiglitazone on the IL1 system. Nonetheless, the downregulatory effect of rosiglitazone on IL1Ra could represent a harmful effect of TZDs in MetSyn, potentially contributing to the recently reported increased risk of myocardial infarction (33) and chronic heart failure $(34,35)$ during such therapy.

In contrast to our in vivo data, our in vitro data in THP-1 monocytes suggest that rosiglitazone also may possess anti-inflammatory effects on the IL1 system, at least in some concentrations, with suppressive effects on IL1 $\beta$ levels combined with enhancing effects on IL1Ra. Similar anti-inflammatory effects on the IL1 system in vitro have also been reported by others in THP-1 monocytes (36) and synovial fibroblasts (37). Thus, although our in vivo data clearly suggest inflammatory net effect on the IL1 system during rosiglitazone therapy, representing the main finding in the present study, our in vitro data illustrate the complex effects of these medications, potentially exhibiting anti-inflammatory effects in certain tissues or cells at least at certain concentrations.

In addition to its inflammatory effect on the IL1 system, rosiglitazone was found to decrease IL10 levels further suggesting inflammatory effects of this medication. On the other hand, rosiglitazone increased plasma levels of sTNF-R1 and tended to decrease MCP1 and CRP, which may reflect anti-inflammatory effects. Furthermore, rosiglitazone markedly reduced uric acid levels. A raised level of uric acid is a phenotypic characteristic of patients with MetSyn, potentially reflecting enhanced inflammation and oxidative stress (17). The decrease in uric acid levels during rosiglitazone therapy could therefore mirror beneficial net effects on these processes in MetSyn. These findings suggest that the in vivo effects of TZDs may be rather complex including inflammatory but also potential anti-inflammatory effects.

During rosiglitazone therapy, there was an increase in serum levels of total cholesterol, reflecting an increase in LDL cholesterol without any significant changes in HDL cholesterol, and the apolipoprotein B/A1 ratio was increased. A similar pattern on lipid parameters has also been reported by others (reviewed by $(38,39)$ ). It has been suggested that these side effects and their potential for cardiac risk must be weighed against the beneficial effects on glucose metabolism. In fact, recent studies have suggested that rosiglitazone may increase the risk of fractures and cardiac disease, although the cardiac disease observed was in the form of heart failure rather than ischemic heart disease events (33-35).

The present study has certain limitations such as a low number of subjects, and the study period was relatively short. Moreover, although the study was randomized and double-blind placebo-controlled, the cross-over design may have some limitations. Finally, caution is needed when interpreting data from multiple comparisons in a relatively small study population. Nevertheless, the current study shows potentially inflammatory effects of rosiglitazone in patients with MetSyn, primarily reflecting downregulatory effects on the naturally occurring IL1 inhibitor, IL1Ra. However, the effects of TZDs are rather complex, and their net effect on cardiovascular risk in MetSyn and other patient populations should be further investigated.

\section{Declaration of interest}

The authors declare that there is no conflict of interest that could be perceived as prejudicing the impartiality of the research reported.

\section{Funding}

This work was supported by Helse Sør, Medinnova Foundation, Freia Found, Eckbo's Foundation, Blix Family Foundation and Rikshospitalet University Hospital.

\section{Acknowledgements}

The assistance of Ellen Lund Sagen, Ragnhild Kleve, Elin Kjekshus, and Cecilia Guevara is greatly appreciated.

\section{References}

1 Jiamsripong P, Mookadam M, Alharthi MS, Khandheria BK \& Mookadam F. The metabolic syndrome and cardiovascular disease: part 2. Preventive Cardiology 200811 223-229.

2 Hansson GK. Inflammation, atherosclerosis, and coronary artery disease. New England Journal of Medicine 2005352 1685-1695.

3 Sjoholm A \& Nystrom T. Endothelial inflammation in insulin resistance. Lancet $2005365610-612$.

4 Jacobs M, van Greevenbroek MM, van der Kallen CJ, Ferreira I, Blaak EE, Feskens EJ, Jansen EH, Schalkwijk CG \& Stehouwer CD. Low-grade inflammation can partly explain the association between the metabolic syndrome and either coronary artery disease or severity of peripheral arterial disease: the CODAM study. European Journal of Clinical Investigation 200939 437-444. 
5 Rabe K, Lehrke M, Parhofer KG \& Broedl UC. Adipokines and insulin resistance. Molecular Medicine 2008 14 741-751.

6 Smith SC Jr. Multiple risk factors for cardiovascular disease and diabetes mellitus. American Journal of Medicine 2007120 S3-S11.

7 Yki-Jarvinen H. Thiazolidinediones. New England Journal of Medicine 2004351 1106-1118.

8 Quinn CE, Hamilton PK, Lockhart CJ \& McVeigh GE. Thiazolidinediones: effects on insulin resistance and the cardiovascular system. British Journal of Pharmacology 2008153 636-645.

9 Hetzel J, Balletshofer B, Rittig K, Walcher D, Kratzer W, Hombach V, Haring HU, Koenig W \& Marx N. Rapid effects of rosiglitazone treatment on endothelial function and inflammatory biomarkers. Arteriosclerosis, Thrombosis, and Vascular Biology 2005 25 1804-1809.

10 Duan SZ, Usher MG \& Mortensen RM. Peroxisome proliferatoractivated receptor-gamma-mediated effects in the vasculature. Circulation Research 2008102 283-294.

11 Marx N, Imhof A, Froehlich J, Siam L, Ittner J, Wierse G, Schmidt A, Maerz W, Hombach V \& Koenig W. Effect of rosiglitazone treatment on soluble CD4OL in patients with type 2 diabetes and coronary artery disease. Circulation $2003 \mathbf{1 0 7}$ 1954-1957.

12 Kalaitzidis RG, Sarafidis PA \& Bakris GL. Effects of thiazolidinediones beyond glycaemic control. Current Pharmaceutical Design 200915 529-536.

13 Aukrust P, Berge RK, Muller F, Ueland PM, Svardal AM \& Froland SS. Elevated plasma levels of reduced homocysteine in common variable immunodeficiency - a marker of enhanced oxidative stress. European Journal of Clinical Investigation 199727 723-730.

14 Holven KB, Scholz H, Halvorsen B, Aukrust P, Ose L \& Nenseter MS. Hyperhomocysteinemic subjects have enhanced expression of lectin-like oxidized LDL receptor-1 in mononuclear cells. Journal of Nutrition 2003133 3588-3591.

15 Matthews DR, Hosker JP, Rudenski AS, Naylor BA, Treacher DF \& Turner RC. Homeostasis model assessment: insulin resistance and beta-cell function from fasting plasma glucose and insulin concentrations in man. Diabetologia $1985 \mathbf{2 8} 412-419$.

16 Aukrust P, Bjornsen S, Lunden B, Otterdal K, Ng EC, Ameln W, Ueland T, Muller F, Solum NO, Brosstad F \& Frøland SS. Persistently elevated levels of von Willebrand factor antigen in HIV infection. Downregulation during highly active antiretroviral therapy. Thrombosis and Haemostasis $2000 \mathbf{8 4} 183-187$.

17 Arora S, Aukrust P, Ueland T, Broch K, Simonsen S, Gude E, Fiane AE, Geiran O, Wergeland R, Andreassen AK \& Gullestad L. Elevated serum uric acid levels following heart transplantation predict all-cause and cardiac mortality. European Journal of Heart Failure $2009101005-1013$.

18 Charo IF \& Taubman MB. Chemokines in the pathogenesis of vascular disease. Circulation Research $200495858-866$.

19 Granowitz EV, Santos AA, Poutsiaka DD, Cannon JG, Wilmore DW, Wolff SM \& Dinarello CA. Production of interleukin-1-receptor antagonist during experimental endotoxaemia. Lancet 1991338 1423-1424.

20 Waehre T, Yndestad A, Smith C, Haug T, Tunheim SH, Gullestad L, Froland SS, Semb AG, Aukrust P \& Damas JK. Increased expression of interleukin-1 in coronary artery disease with downregulatory effects of HMG-CoA reductase inhibitors. Circulation 2004109 1966-1972.

21 Giannini S, Serio M \& Galli A. Pleiotropic effects of thiazolidinediones: taking a look beyond antidiabetic activity. Journal of Endocrinological Investigation 200427 982-991.

22 Meisner F, Walcher D, Gizard F, Kapfer X, Huber R, Noak A, Sunder-Plassmann L, Bach H, Haug C, Bachem M, Stojakovic T, Marz W, Hombach V, Koenig W, Staels B \& Marx N. Effect of rosiglitazone treatment on plaque inflammation and collagen content in nondiabetic patients: data from a randomized placebocontrolled trial. Arteriosclerosis, Thrombosis, and Vascular Biology 200626 845-850.

23 Kim HJ, Kang ES, Kim DJ, Kim SH, Ahn CW, Cha BS, Nam M, Chung CH, Lee KW, Nam CM \& Lee HC. Effects of rosiglitazone and metformin on inflammatory markers and adipokines: decrease in interleukin-18 is an independent factor for the improvement of homeostasis model assessment-beta in type 2 diabetes mellitus. Clinical Endocrinology $200766282-289$.

24 Arend WP, Malyak M, Guthridge CJ \& Gabay C. Interleukin-1 receptor antagonist: role in biology. Annual Review of Immunology $19981627-55$.

25 Dinarello CA. Interleukin-1beta and the autoinflammatory diseases. New England Journal of Medicine 2009360 2467-2470.

26 Fearon WF \& Fearon DT. Inflammation and cardiovascular disease: role of the interleukin-1 receptor antagonist. Circulation $20081172577-2579$.

27 Chamberlain J, Francis S, Brookes Z, Shaw G, Graham D, Alp NJ, Dower $S$ \& Crossman DC. Interleukin-1 regulates multiple atherogenic mechanisms in response to fat feeding. PLoS One 20094 e 5073.

28 Dinarello CA. Blocking IL-1 in systemic inflammation. Journal of Experimental Medicine 2005201 1355-1359.

29 Larsen CM, Faulenbach M, Vaag A, Volund A, Ehses JA, Seifert B, Mandrup-Poulsen $\mathrm{T} \&$ Donath MY. Interleukin-1-receptor antagonist in type 2 diabetes mellitus. New England Journal of Medicine 2007356 1517-1526.

30 Carter KW, Hung J, Powell BL, Wiltshire S, Foo BT, Leow YC, McQuillan BM, Jennens M, McCaskie PA, Thompson PL, Beilby JP \& Palmer LJ. Association of interleukin-1 gene polymorphisms with central obesity and metabolic syndrome in a coronary heart disease population. Human Genetics 2008124 199-206.

31 Juge-Aubry CE, Somm E, Giusti V, Pernin A, Chicheportiche R, Verdumo C, Rohner-Jeanrenaud F, Burger D, Dayer JM \& Meier CA. Adipose tissue is a major source of interleukin-1 receptor antagonist: upregulation in obesity and inflammation. Diabetes 200352 1104-1110.

32 Cartier A, Bergeron J, Poirier P, Almeras N, Tremblay A, Lemieux I \& Despres JP. Increased plasma interleukin-1 receptor antagonist levels in men with visceral obesity. Annals of Medicine 2009. In Press DOI: 10.1080/07853890903022801.

33 Nissen SE \& Wolski K. Effect of rosiglitazone on the risk of myocardial infarction and death from cardiovascular causes. New England Journal of Medicine 2007356 2457-2471.

34 Home PD, Pocock SJ, Beck-Nielsen H, Curtis PS, Gomis R, Hanefeld M, Jones NP, Komajda M \& McMurray JJ. Rosiglitazone evaluated for cardiovascular outcomes in oral agent combination therapy for type 2 diabetes (RECORD): a multicentre, randomised, open-label trial. Lancet $20093732125-2135$.

35 Home PD, Pocock SJ, Beck-Nielsen H, Gomis R, Hanefeld M, Jones NP, Komajda M \& McMurray JJ. Rosiglitazone evaluated for cardiovascular outcomes - an interim analysis. New England Journal of Medicine 2007357 28-38.

36 Meier CA, Chicheportiche R, Juge-Aubry CE, Dreyer MG \& Dayer JM. Regulation of the interleukin-1 receptor antagonist in THP-1 cells by ligands of the peroxisome proliferator-activated receptor gamma. Cytokine 200218 320-328.

37 Moulin D, Bianchi A, Boyault S, Sebillaud S, Koufany M, Francois M, Netter P, Jouzeau JY \& Terlain B. Rosiglitazone induces interleukin-1 receptor antagonist in interleukin-1betastimulated rat synovial fibroblasts via a peroxisome proliferatoractivated receptor beta/delta-dependent mechanism. Arthritis and Rheumatism 200552 759-769.

38 Derosa G \& Salvadeo SA. Pioglitazone and rosiglitazone: effects of treatment with a thiazolidinedione on lipids and non conventional cardiovascular risk factors. Current Clinical Pharmacology 20083 77-84.

39 Rizzo M, Christ ER, Rini GB, Spinas GA \& Berneis K. The differential effects of thiazolidindiones on atherogenic dyslipidemia in type 2 diabetes: what is the clinical significance? Expert Opinion on Pharmacotherapy 20089 2295-2303.

Received 11 November 2009

Accepted 18 November 2009 